\title{
Current and Potential Treatments for Reducing Campylobacter Colonization in Animal Hosts and Disease in Humans
}

\author{
Tylor J. Johnson, Janette M. Shank and Jeremiah G. Johnson* \\ Department of Microbiology, The University of Tennessee, Knoxville, TN, USA
}

Campylobacter jejuni is the leading cause of bacteria-derived gastroenteritis worldwide. In the developed world, Campylobacter is usually acquired by consuming undercooked poultry, while in the developing world it is often obtained through drinking contaminated water. Once consumed, the bacteria adhere to the intestinal epithelium or mucus layer, causing toxin-mediated inhibition of fluid reabsorption from the intestine and invasion-induced inflammation and diarrhea. Traditionally, severe or

\section{OPEN ACCESS}

Edited by: Heather K. Allen, National Animal Disease Center, USA

Reviewed by: Matthew Jon Sylte, United States Department of Agriculture, USA Catherine M. Logue, lowa State University, USA

Michael Edward Konkel, Washington State University, USA

*Correspondence:

Jeremiah G. Johnson jjohn358@utk.edu

Specialty section: This article was submitted to Antimicrobials, Resistance and Chemotherapy,

a section of the journal

Frontiers in Microbiology

Received: 04 January 2017 Accepted: 08 March 2017

Published: 23 March 2017

Citation:

Johnson TJ, Shank JM and

Johnson JG (2017) Current and Potential Treatments for Reducing Campylobacter Colonization in Animal Hosts and Disease in Humans.

Front. Microbiol. 8:487. doi: 10.3389/fmicb.2017.00487 prolonged cases of campylobacteriosis have been treated with antibiotics; however, overuse of these antibiotics has led to the emergence of antibiotic-resistant strains. As the incidence of antibiotic resistance, emergence of post-infectious diseases, and economic burden associated with Campylobacter increases, it is becoming urgent that novel treatments are developed to reduce Campylobacter numbers in commercial poultry and campylobacteriosis in humans. The purpose of this review is to provide the current status of present and proposed treatments to combat Campylobacter infection in humans and colonization in animal reservoirs. These treatments include anti-Campylobacter compounds, probiotics, bacteriophage, vaccines, and anti-Campylobacter bacteriocins, all of which may be successful at reducing the incidence of campylobacteriosis in humans and/or colonization loads in poultry. In addition to reviewing treatments, we will also address several proposed targets that may be used in future development of novel anti-Campylobacter treatments.

Keywords: Campylobacter, chicken colonization, anti-infectves, food safety, antibiotic resistance

\section{INTRODUCTION}

Campylobacter jejuni is the leading global cause of gastroenteritis derived from bacteria. The substantial increase of both incidence and prevalence of campylobacteriosis in Europe, Australia, and North America is troubling, and data from Asia, Africa, and the Middle East indicate that campylobacteriosis has become endemic in these areas, especially in young children (Kaakoush et al., 2015). In the United States, treatment of acute disease and post-infectious disorders

\footnotetext{
Abbreviations: CCCP, carbonyl cyanide $m$-chlorophenylhydrazone; CPS, capsule polysaccharide; EO, essential oil; GBS, Guillain-Barré syndrome; IC50, inhibitory concentration 50; LOS, lipo-oligosaccharides; MIC, minimum inhibitory concentration; NHP, non-human primate; NP, nanoparticle; OE, olive leaf extract; OMP, outer membrane protein; QS, quorum sensing; RND, resistance-nodulation-cell division; TE, thyme ethanolic extract; TE-R, thyme hydrodistillation residue.
} 
associated with Campylobacter infection, cost approximately $\$ 1.7$ billion USD annually (Maue et al., 2014). Following ingestion of the bacterium, Campylobacter adheres to and invades the epithelial cells lining the gastrointestinal tract, inducing a potent inflammatory response (Backert et al., 2013; Samuelson et al., 2013). This results in moderate to severe diarrhea that may be accompanied by frank blood in the stool, abdominal cramps, and fever. While campylobacteriosis is typically characterized by gastroenteritis, it can also lead to septicemia, post-infectious arthritis, GBS, or Miller Fisher syndrome (Goldstein et al., 2016). Additionally, Campylobacter spp. have recently been associated with inflammatory bowel diseases such as Crohn's disease and ulcerative colitis (Kaakoush et al., 2014a,b).

Illnesses associated with Campylobacter are a greater burden in developing countries. While infection in immunocompetent patients in the developed world is usually self-limiting, it has been observed to persist in the gastrointestinal tracts of some patients, particularly young children in the developing world, that leads to stunting (Amour et al., 2016). Similarly, persistent diarrhea and severe bacteremia associated with Campylobacter spp. have been observed in HIV/AIDS patients (Coker et al., 2002). As such, morbidity and mortality caused by Campylobacter is increased among HIV positive individuals, particularly in the developing world (Tee and Mijch, 1998; Guerry et al., 2012).

In the developed world, $C$. jejuni is a leading cause of food-borne illness primarily due to its ability to asymptomatically colonize agriculturally relevant animals, including chickens (Johnson et al., 2015). In poultry flocks, natural colonization of chicks occurs within $2-3$ weeks of hatching via horizontal contamination from the environment and birds typically remain colonized for life (Sahin et al., 2003). Since domestic and wild birds are the microorganism's primary reservoir, they may carry up to $10^{9} \mathrm{CFU}$ Campylobacter per gram of cecal contents (Meunier et al., 2016b). The microorganism can then spread from the intestines of poultry to meat during processing.

According to a survey of Campylobacters in England and Wales, C. jejuni is responsible for approximately $90 \%$ of campylobacteriosis cases and $C$. coli are responsible for the remaining 10\% (Gillespie et al., 2002). Other Campylobacter species can also cause disease, but they are rarely involved (Meunier et al., 2016b). Human infection can occur following ingestion of as few as 500 Campylobacter cells; however, the sample size in this particular study was small $(n=1)$ (Robinson, 1981). Another study that determined the infectious dose of Campylobacter required to result in diarrhea or fever, found that no clear correlation was observed between dose and the percentage of participants that presented with these symtoms. Similarly, no dose response was observed for colonization as all doses resulted in $100 \%$ of humans presenting with positive stool cultures (Black et al., 1988).

Not surprisingly, as chickens serve as a major source of human infections in the developed world, it has been proposed that to decrease the incidence of campylobacteriosis, avian colonization must be combatted (Meunier et al., 2016b). Since it has been predicted that decreasing Campylobacter colonization of poultry by $2-\log _{10}$ will reduce human infections by 30 -fold, much research has focused on understanding colonization of poultry by Campylobacter, since even a small reduction could have an enormously positive impact on human health (Rosenquist et al., 2003). While ingestion of contaminated poultry is the primary mode of infection in developed parts of the world, ingestion of contaminated water is commonly responsible for Campylobacter infections in developing parts of the world (Kaakoush et al., 2015).

Since campylobacteriosis is usually self-limiting and treatment with antibiotics typically only decreases the duration of gastrointestinal symptoms by 1.32 days, some groups have advised against antibiotic treatment in uncomplicated campylobacteriosis cases (Ternhag et al., 2007). In severe or prolonged cases that are generally associated with immunocompromised persons or young children, patients are treated with antibiotics from the macrolide (erythromycin) or quinolone (ciprofloxacin) classes (Longenberger et al., 2013; Kovač et al., 2015). Unfortunately, the emergence of antibiotic resistant Campylobacter necessitates the development of novel antimicrobials (Kumar et al., 2016). For example, the use of fluoroquinolones in poultry production coincided with the emergence of ciprofloxacin-resistant Campylobacter in humans (Moore et al., 2006). As such, the Centers for Disease Control and Prevention reported an increase in ciprofloxacin resistance in Campylobacter from 13 to 25\% occurred between 1997 and 2011 (Hampton, 2013). More concerning, some European Union Member states reported up to a $91.5 \%$ incidence of quinolone resistant Campylobacter (EFSA, 2014). Similarly, it was determined that the incidence of ciprofloxacin resistance in Campylobacter isolates from raw chicken in South Korea was approximately 92\% (Han et al., 2007) and 100\% in clinical isolates from children in Thailand (Serichantalergs et al., 2007). Because of this prevalence, international travel-associated infections in the United States are often caused by quinolone-resistant Campylobacter isolates, exhibiting resistant rates of $60 \%$; this is compared to the $13 \%$ of non-travel related cases (Ricotta et al., 2014). These data show that antibiotic resistant Campylobacter is a global issue that has far-reaching effects on human health.

Since the incidence of antibiotic resistance in Campylobacter is increasing, the severity of post-infectious disorders is becoming better understood, and the economic burden associated with campylobacteriosis in humans is substantial, it is essential that novel interventions be developed to reduce the incidence of Campylobacter colonization in commercial poultry and reduce the number of campylobacteriosis cases in humans. Thus, the purpose of this review is to provide the status of several current and proposed treatments to combat Campylobacter infection in humans either directly or through reducing colonization of poultry. We will also address potential targets for future research directed toward developing novel anti-Campylobacter treatments.

\section{Campylobacter RESERVOIRS AND SOURCES OF INFECTION}

One factor that contributes to the widespread nature of human Campylobacter infections is the organism's ubiquity in various 


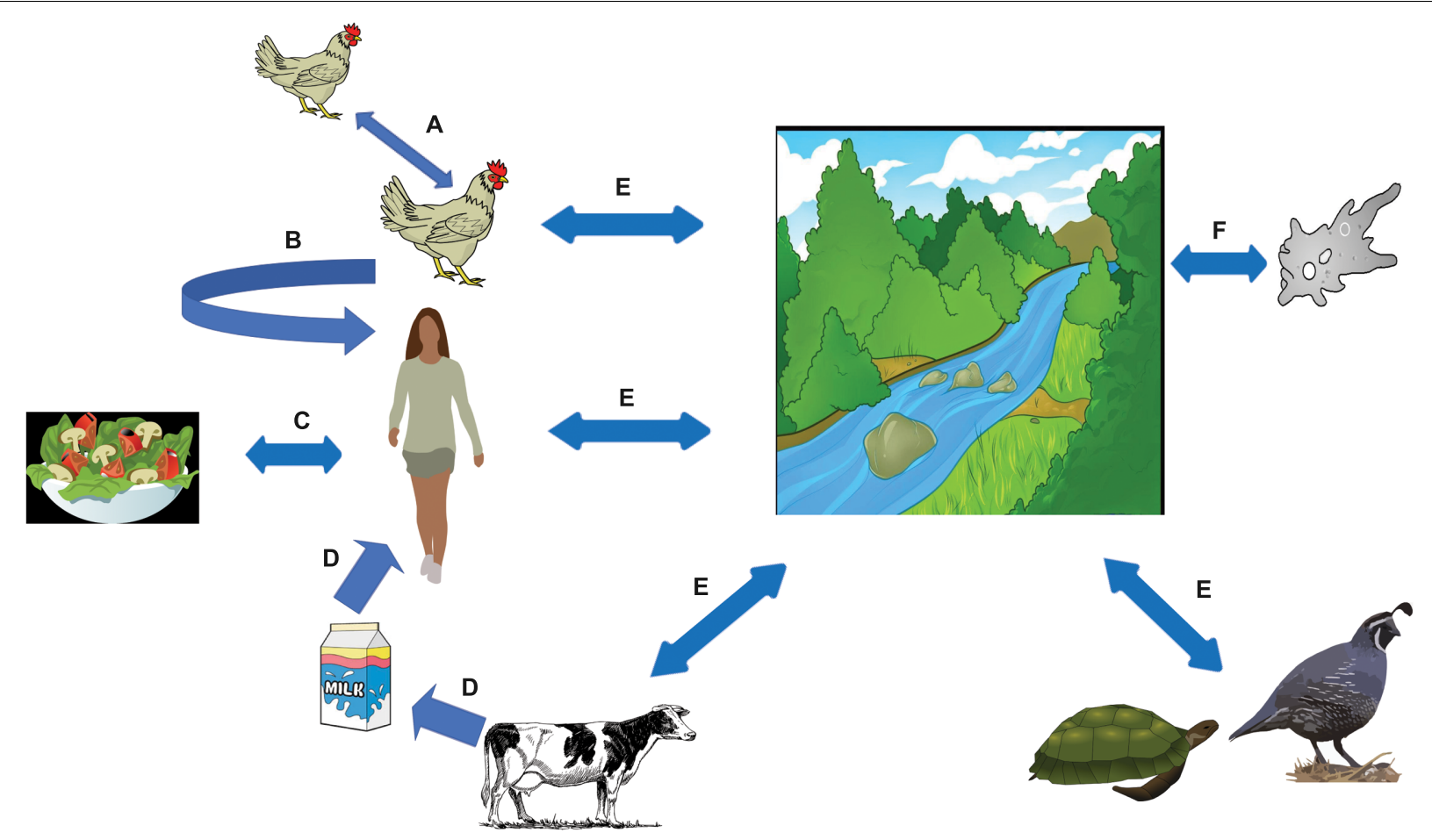

FIGURE 1 | Campylobacter spp. modes of infection. Campylobacter spp. reside in large numbers in the gastrointestinal tract of chickens, where the bacteria is spread throughout the flock via the fecal-oral route (A) (Young et al., 2007). In the developed world, Campylobacter is usually acquired by consuming under-cooked poultry (B). However, outbreaks have been associated with different types of fresh produce (C) (Kärenlampi and Hänninen, 2004) and dairy products (D) (El-Zamkan and Hameed, 2016). Campylobacter spp. is frequently found in surface water, usually from contamination from animal feces, and has been known to infect humans (E) (Mughini-Gras et al., 2016). It has also been postulated that Campylobacter may be able to infect amoebae, which may serve as a reservoir (F) (Axelsson-Olsson et al., 2005).

domestic and wild animals (Figure 1). As mentioned above, avian species are the primary reservoir of Campylobacter spp., where they reside asymptomatically in large numbers within the lower gastrointestinal tracts of these animals (Johnson et al., 2015; Jonaidi-Jafari et al., 2016; Weis et al., 2016). As such, Campylobacter is commonly isolated from poultry, including chickens and turkeys, but also other domestic and wild avian species, such as crows, ducks, quail, and starlings (Jonaidi-Jafari et al., 2016; Weis et al., 2016). Even though the naturally high body temperature $\left(40-42^{\circ} \mathrm{C}\right)$ (Johnston et al., 2016; Hamrita and Conway, 2017) of avian species provides an ideal environment for Campylobacter growth, the bacterium also commonly colonizes domestic livestock, including cattle, goats, pigs, and sheep (Manyi-Loh et al., 2016). For example, in beef and dairy cattle fecal samples in Finland, 31.1\% of samples contained Campylobacter spp. (Hakkinen et al., 2007). Like many foodborne enteric pathogens, the presence of Campylobacter in so many animal species not only contributes to the prevalence of food-to-human transmission, but also environment-to-human transmission due to the abundance of agricultural contaminants in the environment.

Since Campylobacter can colonize such a broad range of animals, it is of interest whether some strains exhibit a predilection for certain hosts. Such observations would not only be useful in understanding the differences that may impart host preferences, but could also enable the epidemiological study of infection sources. In a genome-wide association study, Weis et al. (2016) compared Campylobacter strains isolated from humans, NHPs, chickens, cows, crows, goats, and sheep. The authors found that $17 \%$ of Campylobacter spp. isolated from crows were highly similar to those isolated from humans, primates, and sheep, indicating that multiple genotypes exist within individual bacterial species. With C. jejuni, it also elucidated host origin, providing evidence for host-species adaptation. Still, further investigation is needed to understand the genomes of naturally occurring Campylobacter strains from different environments and how they may provide evidence for host colonization mechanisms and zoonotic spread of the pathogen (Weis et al., 2016). As such, the study of these diverse strains and the insights they provide may yield promising targets for future research aimed at developing interventions that prevent transmission and persistence amongst animal reservoirs.

\section{CAMPYLOBACTER BIOFILMS}

Another trait of Campylobacter spp. that allows for environmental persistence is its ability to form biofilms on various abiotic surfaces, i.e., water distribution systems (Kalmokoff et al., 2006; Young et al., 2007; Maal-Bared et al., 
2012; Bae et al., 2014; Duarte et al., 2016). Biofilms enable the microorganism to survive in environments it normally would not be able to, allowing it to acquire adequate nutrients while also providing protection from antimicrobials, including the disinfectants water sources are typically treated with (Simões et al., 2010). Thus, biofilms make it possible for Campylobacter to survive in water for up to 3 weeks and possibly longer (Lehtola et al., 2006). One mechanism in Campylobacter that is associated with biofilm formation is quorum sensing (QS). QS is a population-dependent cell-to-cell signaling mechanism involving the production and detection of extracellular signaling molecules (Elvers and Park, 2002). As QS communication has been linked to bacterial proliferation in foods and food spoilage, QS inhibition is a promising target to control Campylobacter and to ensure food safety (Nazzaro et al., 2013; Duarte et al., 2016). Since biofilm formation also increases the efficiency with which Campylobacter develops antibiotic resistance by horizontal gene transfer (discussed further below), the mechanisms responsible for biofilm formation are potential targets for future research aimed at mitigating the spread of genetic determinants responsible for resistance.

\section{ANTIBIOTIC RESISTANCE DETERMINANTS IN CAMPYLOBACTER}

As antibiotic resistance becomes increasingly prevalent in Campylobacter, the need for novel antimicrobial strategies to reduce Campylobacter in poultry and poultry products becomes more critical. This is primarily driven by the need to reduce the economic and human health burden incurred by antibiotic-resistant campylobacteriosis, (Duarte et al., 2016). A thorough comprehension of antibiotic resistance mechanisms in Campylobacter would aid in the development of novel antiCampylobacter treatments, either by serving as targets themselves or by allowing for the development of strategies that circumvent resistance mechanisms.

Campylobacter can acquire antibiotic resistance by spontaneous mutations and horizontal gene transfer via natural transformation, transduction, and conjugation (Kumar et al., 2016). For example, the presence of conjugative plasmids containing tetO, have substantial roles in disseminating tetracycline resistance in Campylobacter (Pérez-Boto et al., 2014). Of the known antibiotic resistance determinants in Campylobacter, CmeABC is the best characterized (Martinez and Lin, 2006; Oh and Jeon, 2015). CmeABC is an energy-dependent multidrug efflux pump, and when the efflux pump inhibitor carbonyl cyanide $m$-chlorophenylhydrazone (CCCP) was added to $C$. jejuni 81-176 cultures, a rapid and substantial increase in cell-associated ciprofloxacin occurred (Lin et al., 2002). CmeABC consists of three protein components: the periplasmic fusion protein (CmeA), the inner membrane drug transporter (CmeB), and the OMP (CmeC) (Lin et al., 2002). As a result, an isogenic cmeB mutant of $C$. jejuni 21190 was found to be more susceptible to antibiotics (Lin et al., 2002). Antibiotic resistance in Campylobacter has also been shown to correspond to active site mutations in the DNA gyrase subunit A (gyrA) (Wieczorek and Osek, 2013; Kovač et al., 2015; Kumar et al., 2016).

In an attempt to directly target an antimicrobial resistance mechanism, it was previously shown that some phenolic compounds (i.e., gallic acid and taxifolin) significantly reduced the expression of the CmeABC efflux pump and that they could be used synergistically with antibiotics to inhibit $C$. jejuni by impacting both antimicrobial influx and efflux (Oh and Jeon, 2015). One promising use of phenolic compounds that has been proposed is the development of antimicrobial adjuvants, which would inhibit the function of resistant determinants, ultimately decreasing the ability of these strains to survive antibiotic treatment (Oh and Jeon, 2015). Since this approach would re-sensitize Campylobacter to antibiotics, it could augment the utility of existing antibiotics. Because of this, it has been suggested that phenolic compounds could be used as dietary supplements during antibiotic treatment of human campylobacteriosis (Wright, 2000; Pagès and Amaral, 2009; Oh and Jeon, 2015).

Since many $C$. jejuni strains are mutable and naturally competent, this species exhibits wide genetic diversity and variability, which increases the frequency of Campylobacter antibiotic resistance and virulence (Wilson et al., 2003; Young et al., 2007). Bae et al. (2014), reported that once C. jejuni develops resistance to antibiotics, those genetic determinants can be transferred in planktonic cultures, but are most efficiently transmitted in biofilms. C. jejuni exhibits donor restriction by an unknown mechanism as it takes up free DNA from C. jejuni more readily than it does from other bacterial strains (Wang and Taylor, 1990). The frequency of this transfer is also related to bacterial cell density since transformation efficiency correlates with increased bacterial numbers, presumably due to an increase of extracellular DNA in cultures (Wilson et al., 2003). Campylobacter also increases free DNA uptake under oxygen-limited conditions, like the gastrointestinal tract, which provides evidence for environmental regulation of horizontal gene transfer in vivo (Young et al., 2007). Due to the role these mechanisms play in the spread of antibiotic resistance, identifying interventions that inhibit natural transformation in Campylobacter are a goal of many researchers in the field.

\section{ANTI-Campylobacter COMPOUNDS}

Another area that has been pursued to reduce the prevalence of Campylobacter in agriculture, is the development of antiCampylobacter compounds, such as small molecule inhibitors. Like similar work in other bacteria, these compounds can be directed against specific processes that are known to contribute to colonization or they can be developed as narrow-spectrum growth inhibitors. Whichever approach is taken; the goal is the same: the reduction of Campylobacter in agriculture using compounds that are not used in human medicine. Recently, Johnson et al. (2015) conducted a study to identify small molecule inhibitors of Campylobacter flagellar expression - a known colonization factor. Screening a library of approximately 147,000 small molecules, the authors identified compounds 
that modestly inhibited flagellar motility and several other compounds, termed 'campynexins', that inhibited Campylobacter growth in vitro (Johnson et al., 2015). The campynexins exhibited robust growth inhibition with most inhibitory concentration 50s (IC50s) $<10 \mu \mathrm{M}$ and, using Helicobacter pylori, were found to only inhibit members of the Campylobacter genus. Not surprisingly in these types of studies, the molecules of greatest interest are those that specifically exhibit activity toward Campylobacter - to minimize the effects on beneficial microbes in the gastrointestinal tract - and demonstrate efficacy in vivo.

According to Kumar et al. (2016), anti-Campylobacter small molecule inhibitors are considered bacteriostatic or bactericidal at a concentration of $200 \mu \mathrm{M}$. This study found 10 novel compounds with anti-Campylobacter activity, including molecules that induce intracellular clearance from human intestinal Caco-2 cells at concentrations as low as $25 \mu \mathrm{M}$ (Kumar et al., 2016). A positive trait of these molecules is that they possessed low cytotoxicity to Caco-2 cells and no hemolytic activity against sheep red blood cells. The antiCampylobacter molecules described in this study belong to five chemical classes that have been established as antimicrobial: aryl amines, piperazines, pyridiazinones, sulfonamides, and piperidines.

Treating Campylobacter-colonized chickens with these antiCampylobacter molecules and evaluating the reduction in colonization is one area that should be investigated further. In the campynexin study, day-of-hatch chicks were used to evaluate the impact of the small molecules on gastrointestinal colonization (Johnson et al., 2015). While one of these compounds was found to significantly reduce Campylobacter loads in vivo, its lack of consistency indicates that further development from a medicinal chemistry perspective is needed. A potential extension of this work is the treatment of acute and persistent campylobacteriosis in immunocompromised patients that are infected with antibiotic resistant strains. Mice (Stahl et al., 2014), rats (Sung et al., 2013), and ferrets (Fox et al., 1987) have all been used as animal models for campylobacteriosis and should be considered as candidates for in vivo studies investigating the efficacy of anti-Campylobacter molecules at treating human infection.

Ideally, administration of anti-Campylobacter compounds will be as feed or water additives; however, there are several caveats with these approaches. Most obvious is that consumers are generally concerned with the use of synthetic additives in animal feed and their possible dissemination to the meat we consume. This has led researchers to pursue the development and use of natural additives in animal feed, rather than synthetic compounds (Verbeke et al., 2007; Brenes and Roura, 2010; Navarro et al., 2015). For example, phenolic compounds of plant origin have been shown to have anti-Campylobacter activity (Klanènik et al., 2012). In one study, compounds with the highest anti-Campylobacter activity were rosmarinic and carnosic acids. This study showed that inactivation of the efflux gene, cmeB, caused Campylobacter to be significantly more sensitive to the phenolic compounds, suggesting that transport of the compounds from the intracellular compartment is required for resistance.
Additionally, Campylobacter was shown to be sensitive to a variety of plant extracts including basil, campsicum, cinnamon bark, clove, garlic, laurel, lemon, lemon grass, lemon myrtle, mandarin, bitter and sweet orange, oregano, rosemary, sage, and thyme (Navarro et al., 2015). Several other plant-derived compounds, including anethole, carvacrol, cinnamaldehyde, citral, curcumin, eugenol, thymol, and vanillin have also been shown to have anti-Campylobacter activity, though the mechanism of toxicity is unknown (Navarro et al., 2015). In this study, oregano essential oil had the strongest anti-Campylobacter activity with a MIC of $0.0038 \%$ and formic acid was the most toxic organic acid with an MIC of $0.025 \%$. Additionally, $\mathrm{Lu}$ et al. (2011) investigated the anti-Campylobacter activity of garlic and determined that organosulfur compounds were responsible at a greater level for antimicrobial activity than phenolic compounds. The antimicrobial activities of the garlicderived organosulfur compounds increased as the number of sulfur atoms in the molecule increased. The greatest reduction in Campylobacter in this study was achieved with $25 \mu \mathrm{L}$ garlic concentrate in broth incubated at $35^{\circ} \mathrm{C}$. After 1 day, there were no viable $C$. jejuni cells detected in the medium containing garlic concentrate, compared to the control (medium with no garlic concentrate), which had $7.59 \log _{10} \mathrm{CFU} / \mathrm{mL}$ C. jejuni (Lu et al., 2011).

In other work involving natural products that affect Campylobacter growth and viability, Šikić Pogačar et al. (2015) found that thyme ethanolic extract (TE), thyme post-hydrodistillation residue (TE-R), and $\mathrm{OE}$ reduced adhesion of $C$. jejuni to normal pig small intestinal epitheliaderived cells (PSI c1 cells) (Šikić Pogačar et al., 2015). Since adhesion to intestinal cells is necessary for colonization and disease, compounds that affect Campylobacter adherence may have as much disease-fighting potential as compounds that decrease the viability of Campylobacter (Pogačar et al., 2015).

The development of any of these natural products into effective anti-Campylobacter compounds could decrease the cost of feed formulations since it would eliminate the need of current antimicrobial feed additives (Navarro et al., 2015). As with the synthetic compounds proposed above, the utilization of natural additives as an anti-Campylobacter treatment, is an underexplored area and warrants more research to determine whether additives are transferred to meat products.

While some research has been conducted to identify and characterize anti-Campylobacter compounds, it is still lacking relative to the organism's impact on agriculture and human health. Finding low-cost inhibitors will be essential in combating this increasingly antibiotic-resistant organism, either by mitigating colonization in commercial poultry or treating campylobacteriosis in humans. Regardless of the use, these compounds will need to be safe to both humans and livestock, and ideally would be narrow-spectrum in nature due to the increasing appreciation of the intestinal microbiota in the health of animals, including humans. Currently, neither synthetic nor natural compounds have been sufficiently shown to possess these traits, so much research into their efficacy remains to be performed. 


\section{PROBIOTICS AS A TREATMENT FOR Campylobacter COLONIZATION}

Similar to the increasing appreciation of the intestinal microbiota in animal health, the use of probiotics as an effective means of preventing or reducing the incidence of Campylobacter infection in animal hosts in an antibiotic-free manner has garnered much interest (Fanelli et al., 2015; Kemmett, 2015). In addition to generally reducing the prevalence of Campylobacter, such a practice would, hypothetically, decrease the incidence of antibiotic-resistant strains since it would not require antimicrobials (Kemmett, 2015).

Previous studies that investigated probiotics as anti-Campylobacter treatments have appeared promising (Saint-Cyr et al., 2016). Several of these studies have focused on preventing Campylobacter colonization in broiler chickens at the primary production stage, typically by competitive exclusion of the pathogen by the probiotics (Bratz et al., 2015; Ştef, 2016; Thomrongsuwannakij et al., 2016). The mechanisms of competitive exclusion, includes the occupation of adhesions sites and receptors, secretion of antimicrobial substances, and competition for essential nutrients (Bratz et al., 2015). If a probiotic treatment were successful, such a practice could decrease the Campylobacter load in commercial poultry meat, making it safer for human consumption and reducing the incidence of campylobacteriosis (Fanelli et al., 2015). In addition to treating poultry, probiotics could potentially be used prophylactically for travel-related cases of campylobacteriosis or to treat persistent campylobacteriosis in regions of the world where it is endemic.

The probiotic genera that are most commonly evaluated for their ability to reduce C. jejuni colonization are Lactobacillus, Bacillus, and Enterococcus, as these are well characterized and commonly found in the intestines of animals (Arsi et al., 2015a,b; Thomrongsuwannakij et al., 2016). Researchers have also investigated the efficacy of Bifidobacterium spp. and Saccharomyces cerevisiae at inhibiting C. jejuni colonization and growth (Bratz et al., 2015; Fanelli et al., 2015).

A previous study postulated that Lactobacillus acidophilus, Bacillus subtilis, and Enterococcus faecium were the best probiotic candidates to combat C. jejuni. However, when broiler chickens were treated orally with each of these probiotic strains and later challenged with $C$. jejuni, there was no significant difference in Campylobacter numbers between treatment and control groups (Thomrongsuwannakij et al., 2016). In contrast, another group found that Lactobacillus helveticus strain R0052 reduced C. jejuni 81-176 and C. jejuni 11168 invasion of T84 cells by 41 and $35 \%$, respectively (Wine et al., 2009). It was observed that L. helveticus adhered to the epithelial cells, suggesting that competitive exclusion may have contributed to the reduction in C. jejuni invasion (Wine et al., 2009). While this result was statistically significant, it was performed in vitro and such a modest reduction is unlikely to have much of an effect on product safety. In a similar study, 117 bacterial species found in the ceca of broiler chickens, were screened, and three bacterial species were determined to significantly decrease Campylobacter colonization of chickens (Arsi et al., 2015a).
Another study reported that multiple Lactobacillus strains inhibited the growth of $C$. jejuni in vitro due to organic acid production by these microorganisms (Bratz et al., 2015). Lactobacillus spp. lower $\mathrm{pH}$ to create a more hospitable environment for themselves, an effect that is increased when multiple strains are present (Wang et al., 2014; Kemmett, 2015; Wooten et al., 2016). Unfortunately, using probiotics to eliminate Campylobacter solely by lowering $\mathrm{pH}$ may not be efficacious in vivo since the lower gastrointestinal tract is highly buffered by bicarbonate present in pancreatic juices.

An additional study screened 116 bacteria and reported six strains (Bacillus spp.) that reduced C. jejuni counts by at least 1-2 $\log _{10}$ in vivo (Arsi et al., 2015b). These results suggest intracloacal administration of probiotics to broiler chickens is effective and would eliminate the need for encapsulation of the probiotic (Arsi et al., 2015b). Unfortunately, such administration is likely prohibitive from a labor perspective since intracloacal administration of probiotics to large flocks would require a tremendous amount of effort from producers.

Prebiotics, non-digestible food ingredients that promote beneficial bacterial growth in the gut, have also been used to reduce the prevalence of Campylobacter in the broiler chicken gastrointestinal tract. Although they showed no significant impact on their own, prebiotics did significantly decrease the amount of Campylobacter when used in combination with three probiotic species (Arsi et al., 2015a). Similar studies supported these results where Campylobacter loads were reduced in the presence of a combination of prebiotics and probiotics (Peng et al., 2015; Gracia et al., 2016; Guyard-Nicodeme et al., 2016).

Similar to the studies above using bacterial probiotics, $S$. cerevisiae was also found to have an inhibitory effect on Campylobacter. When administered to broiler chickens as a supplement, $S$. cerevisiae was shown to significantly decrease the amount of both Campylobacter and Salmonella in the cecum, feces, breast skin, and neck skin. It was determined this occurred because S. cerevisiae promoted Lactobacillus growth, which competed with Campylobacter and Salmonella for nutrients and attachment sites in the intestines (Fanelli et al., 2015). Taken with the above studies, this treatment is likely not feasible since the direct administration of several Lactobacillus species was unable to induce appreciable reductions in Campylobacter colonization. Also, the promotion of Lactobacillus growth in the presence of $S$. cerevisiae appears contradictory since their abundance in multiple environments is often inversely related. Thus, further studies into the efficacy of $S$. cerevisiae-induced inhibition of Campylobacter should be performed.

In addition to potentially reducing Campylobacter numbers, probiotics can provide several other benefits to their hosts. For example, when either two or four Lactobacillus strains were added to feed, chickens displayed an increase in metabolic rate, nutrient transport capacity, protein production, and adaptability and response to external factors. These effects were most pronounced in chickens administered four Lactobacillus strains from the day they hatched (Ştef, 2016).

Based on the data above, it appears that the use of probiotics is occasionally effective at reducing Campylobacter colonization in chickens, but the methodology and significance of those 
reductions is somewhat questionable. Some of this confusion is due to large discrepancies that have been observed in these studies (Meunier et al., 2016a). Several factors could explain this variation, including the use of different chicken lines, since their sensitivity to Campylobacter or probiotic treatments may vary (Humphrey et al., 2014). Also, differences in Campylobacter strains and doses, as well as differences in administration routes and timing, could lead to these observed discrepancies (Meunier et al., 2016a). Still, Saint-Cyr et al. (2016) proposed that probiotic studies should combine various in vitro and in vivo methods to better account for host complexity, animal feed, and the microbiota. For example, the in vitro models that have been used to investigate anti-Campylobacter activities of probiotics have been based on human cervical or intestinal cell lines. Not surprisingly, the use of avian cell lines may provide a better model if the goal is to identify probiotics that can be used in chickens (Saint-Cyr et al., 2016). Additionally, it may be worthwhile to investigate different and varied bacterial strains to develop an effective anti-Campylobacter probiotic treatment (Saint-Cyr et al., 2016). Lastly, searching for bacterial species that can drastically reduce colonization of Campylobacter in an environment where both already reside may not be the most efficient approach. Instead, researchers may identify more inhibitory probiotics looking elsewhere, with the caveat that those organisms would need to be proficient at colonizing poultry and cannot exert a negative impact on the health or production of the bird. As such, there is likely much more work needed before an effective probiotic is available.

A potential future direction of these probiotic studies would be to determine if the probiotic benefits and Campylobacterinhibiting capabilities would be similar in an animal model of human campylobacteriosis. It has been difficult to conduct this type of research because an animal model that mimics human campylobacteriosis is not frequently used (Mohan, 2015). However, as mentioned above, there are several animals [i.e., mice (Stahl et al., 2014), rats (Sung et al., 2013), and ferrets (Fox et al., 1987)], that have shown potential for this application, but further work needs to be performed to determine their effectiveness.

\section{Campylobacter BACTERIOPHAGE AS A TREATMENT}

Bacteriophages have garnered considerable interest as potential treatments to reduce Campylobacter colonization in commercial poultry. Bacteriophages are viral predators of bacteria that are ubiquitous in the environment and often exhibit exquisite specificity against their host bacterial species. Bacteriophages could potentially be used without impacting the normal microbiota of the host and may be suitable for reducing C. jejuni colonization at the farm level, thus decreasing transmission to the food chain. These attributes make bacteriophages an attractive anti-Campylobacter treatment (El-Shibiny et al., 2009). Thus, the use of bacteriophage as an intervention strategy has been pursued by several research groups (Atterbury et al., 2005; Brüssow et al., 2007; Connerton et al., 2008; El-Shibiny et al., 2009).
Bacteriophages that are effective against Campylobacter have been isolated from multiple sources, including sewage, pig manure, poultry carcasses, and broiler chickens (Grajewski et al., 1985; Salama et al., 1989; Atterbury et al., 2003; El-Shibiny et al., 2005, 2009; Carrillo et al., 2007; Hansen et al., 2007). These bacteriophages, including those identified by Atterbury et al. (2003), represented a spectrum of different lytic classes that can be readily imaged by electron microscopy (El-Shibiny et al., 2009).

Atterbury et al. (2005) determined that $C$. jejuni counts in broiler chickens was significantly lower when bacteriophages were present than when they were absent; means of $5.1 \log _{10}$ $\mathrm{CFU} / \mathrm{g}$ in chickens with bacteriophage and $6.9 \log _{10} \mathrm{CFU} / \mathrm{g}$ in chickens without bacteriophage. Connerton et al. (2008) reported reductions of 2-5 $\log _{10}$ CFU of Campylobacter per gram of chicken cecal contents following treatment with bacteriophage. El-Shibiny et al. (2009) reported that a $7 \log _{10}$ PFU dose of the Campylobacter-specific bacteriophage, CP220, led to a 2 $\log _{10} \mathrm{CFU} / \mathrm{g}$ decline in Campylobacter counts 48 h post-phage inoculation. Since these reductions are in the range of the 2 $\log _{10}$ reductions mentioned earlier, which are hypothesized to result in a 30-fold reduction in human infections, bacteriophages could potentially have a significant impact on human health. Unfortunately, one area these studies are lacking in is the analysis of the chicken microbiota in response to treatment. As with all the strategies above, the goal of these interventions would be to reduce Campylobacter loads specifically while sparing the beneficial inhabitants of the microbiota.

Utilizing bacteriophage to reduce Campylobacter loads in chickens has shown potential at the lab scale; however, there is still work to be done before it can become a feasible treatment at the farm level. The bacteriophage titers necessary to cause a significant reduction in Campylobacter, needs to be minimized. For example, the $7 \log _{10}$ PFU that was needed for a $2 \log _{10}$ reduction of $C$. jejuni (mentioned above) or the $9 \log _{10}$ PFU that was needed for a similar reduction of C. coli (El-Shibiny et al., 2009), indicates that it would not be feasible to treat every chicken on a large farm with bacteriophage doses of these sizes.

Another barrier to developing a successful Campylobacter bacteriophage treatment is that phage, like most predators, seldom eliminate their prey in nature. Rather, the populations of bacteriophage and target bacteria rise and fall in a cyclic manner (Wagenaar et al., 2005; El-Shibiny et al., 2009; Grant et al., 2016). Also, Campylobacter may use genomic instability to avoid predation from phage; however, bacteriophages constantly evolve to circumvent host barriers to infection (Carrillo et al., 2005; El-Shibiny et al., 2009). Also, to develop a successful Campylobacter bacteriophage therapy, the phage must also be able to tolerate gastric pH (El-Shibiny et al., 2009). All of the potential barriers to a successful therapy described above must be addressed before Campylobacter bacteriophage can become feasible at the farm level. It has been postulated that this success will also be based on inoculum volume, inoculation timing, bacteriophage absorption rate, and burst size (Connerton et al., 2011).

While several studies have shown bacteriophage treatment can reduce Campylobacter loads in commercial chickens, to the best 
of our knowledge, no studies have evaluated the capability of bacteriophage to treat Campylobacter colonization in humans. Bacteriophage therapy was used widely throughout the 20th century in Eastern Europe and the former Soviet Union; however, it has not yet been investigated by rigorous scientific standards (Pelfrene et al., 2016). With the increasing incidence of antibioticresistant bacteria, including Campylobacter, it has begun to be re-evaluated as a potential therapeutic for use in human disease. As such, it would be interesting to evaluate the efficacy of bacteriophage at treating human infections. As mentioned above, several animal models exist [i.e., mice (Stahl et al., 2014), rats (Sung et al., 2013), and ferrets (Fox et al., 1987)], that can help determine the effectiveness of bacteriophage, as well as fermentor systems that have previously been used to simulate gut function (Sumeri et al., 2008; Neuman et al., 2014; Kettle et al., 2015).

Due to the relatively low and transient Campylobacter numbers that occur during human infection, it is anticipated that the number of bacteriophage required to reduce colonization during infection, may be lower than those needed to treat the robust and stable population that occurs in chickens. Additionally, the usual specificity of bacteriophage for their host means that treatment may spare beneficial members of the microbiota. This hypothesis is supported by the observation that several types of bacteriophages that exhibit effects toward Campylobacter have been isolated from sources humans are readily exposed to (waterways, livestock, etc.) without any known effects on human gastrointestinal health.

Like any other intervention against Campylobacter, there is a concern that over time the bacteria will develop resistance to the bacteriophage. Fortunately, in a previous study, the incidence of bacteriophage resistance developing in C. jejuni colonized chickens was $2 \%$ and the resistant strains remained a minor component of the population (El-Shibiny et al., 2009). Still, various types of bacteriophage could be used in combination to maintain Campylobacter-free chickens. This may be necessary even in the absence of resistance because, to date, no bacteriophage has exhibited pan-effectiveness against every Campylobacter strain examined. Additionally, microbial resistance to bacteriophage has been correlated with reduced virulence in vivo, indicating that even if a population becomes resistant, it could still benefit human health (Smith et al., 1987; Connerton et al., 2004; Carrillo et al., 2005; El-Shibiny et al., 2009).

At this time, the United States Food and Drug Administration has not approved the pre-harvest use of bacteriophage as an antimicrobial agent. However, a substantial amount of research is currently being conducted globally, which could lead to an accepted treatment (Grant et al., 2016).

\section{Campylobacter VACCINES FOR POULTRY AND HUMANS}

Like the interventions proposed above, vaccination of poultry against Campylobacter could eliminate the microorganism from birds and reduce the incidence of human campylobacteriosis in the developed world (Avci, 2016). Not only would this reduce the occurrence of chicken-to-human Campylobacter transmission, but would also reduce the need for expensive post-harvest treatments (De Zoete et al., 2007; Saxena et al., 2013). At the farm level, Campylobacter has no direct influence on chicken health, productivity, or farmer income (Shane, 2000), thus the farmer would have little incentive to invest resources to reduce the incidence of Campylobacter on the farm. However, the cost of campylobacteriosis to public health systems and the loss of labor productivity is substantial, therefore the main rationale for developing a Campylobacter vaccine would be to reduce potential human health risks, enhance food safety, and decrease the high costs associated with the disease. For the reasons described above, the need for a Campylobacter vaccine may not be driven by the market itself, but will likely require intervention by government agencies (Lund and Jensen, 2016).

Despite the substantial amount of research directed toward vaccine development, currently there is no vaccine on the market to reduce Campylobacter loads in the gastrointestinal tract of chickens (Meunier et al., 2016b). A summary of the antigens used as candidates for Campylobacter vaccines are shown in Table 1. A vaccine has recently been patented that is comprised of a bacterium engineered to produce at least one Campylobacter derived $N$-glycan, and at least one physiologically acceptable diluent, excipient, adjuvant, or carrier (Szymanski and Nothaft, 2016). In this patent, chickens exposed to a ToxC-GT glycoconjugate had a significant reduction of Campylobacter in the cecal contents of challenged chickens. According to the developers, this vaccine composition can be formulated for addition to livestock feed and for administration to poultry.

Other antigens that have been investigated as subunit vaccines for chickens are the periplasmic protein, CjaA, (Buckley et al., 2010) and the adherence and colonization proteins, CadF, FlpA, CmeC, and Dsp (Theoret et al., 2012; Neal-McKinney et al., 2014). Total OMPs (Annamalai et al., 2013) and fusion proteins (Neal-McKinney et al., 2014) have also been evaluated (Meunier et al., 2016b).

TABLE 1 | Antigens used as candidates for Campylobacter vaccines.

\begin{tabular}{ll}
\hline Antigen & Reference \\
\hline ToxC-GT glycoconjugate & Szymanski and Nothaft, 2016 \\
CjaA & Wyszyńska et al., 2004; Buckley et al., 2010 \\
CadF, FlpA, CmeC, and Dsp & Theoret et al., 2012; Neal-McKinney et al., 2014 \\
Total outer membrane proteins & Annamalai et al., 2013 \\
Fusion proteins & Neal-McKinney et al., 2014 \\
Extracytoplasmic proteins & Zeng et al., 2010; Layton et al., 2011; Clark \\
& et al., 2012; Neal-McKinney et al., 2014; \\
& Kobierecka et al., 2016 \\
Campylobacter flagellin & Khoury and Meinersmann, 1995; Widders et al., \\
& 1998; Huang et al., 2010; Tribble et al., 2008; \\
Whole cell vaccine (C. jejuni & Tribble et al., 2008
\end{tabular}

81-176)

Protein subunit vaccine Maue et al., 2014

Campylobacter capsule Schumack et al., 2016

polysaccharide 
A previous study showed that chicken immunization with an avirulent Salmonella strain expressing Campylobacter CjaA substantially reduced the ability of $C$. jejuni to colonize chicken ceca. The authors reported an approximately $6 \log _{10} \mathrm{CFU} / \mathrm{g}$ reduction in cecal contents (Wyszyńska et al., 2004). A more recent study reported the live-attenuated Salmonella vaccine expressing Campylobacter CjaA led to a significant, but far less prominent, reduction of $1.4 \log _{10} \mathrm{CFU} / \mathrm{g} C$. jejuni in chicken cecal contents (Buckley et al., 2010). Similarly, another group evaluated the efficacy of a recombinant attenuated Salmonella enterica strain synthesizing the Dsp protein and observed a $2.5 \log _{10}$ reduction of C. jejuni in chicks after a homologous challenge (Theoret et al., 2012). Neal-McKinney et al. (2014) evaluated several recombinant $C$. jejuni peptides and a fusion protein as chicken vaccines and determined that the greatest reduction in $C$. jejuni colonization was in chickens injected with a recombinant FlaA or FlpA peptide, or a CadF-FlaA-FlpA fusion protein. These vaccinations all resulted in a greater than $2 \log _{10}$ reduction in $C$. jejuni colonization. Advanced delivery systems have also been evaluated; biodegradable and biocompatible poly (lactide-co-glycolide) NP encapsulated OMPs of C. jejuni were used to vaccinate chickens (Annamalai et al., 2013). In this study, C. jejuni colonization of the chicken cloaca and ceca were below the limit of detection in the vaccinated groups following 7-days post-challenge.

Another protein that has been investigated as a potentially effective immunogen is Campylobacter flagellin, which is the immunodominant Campylobacter antigen (Meunier et al., 2016b). Studies have shown induction of an immune response toward Campylobacter flagellin, but this was not correlated with a decrease in colonization of the chicken gut (Khoury and Meinersmann, 1995; Widders et al., 1998; Huang et al., 2010; Meunier et al., 2016b).

Less targeted approaches using numerous conserved extracytoplasmic proteins have also been evaluated for Campylobacter vaccine development (Wyszyńska et al., 2004; Buckley et al., 2010; Zeng et al., 2010; Layton et al., 2011; Clark et al., 2012; Neal-McKinney et al., 2014; Kobierecka et al., 2016). In these studies, the median reduction of C. jejuni in chicken cecal contents ranged from $6 \log _{10}$ (Wyszyńska et al., 2004) to less than $1 \log _{10}$ (Buckley et al., 2010). In these two studies, vaccines were administered at comparable doses on identical days post-hatch. However, Wyszyńska et al. (2004) did not report the course of intestinal colonization, systemic translocation of the vaccine strain, or whether the vaccine strain was present at the point of challenge (Buckley et al., 2010). Buckley et al. (2010) suggested that the line and immune status of the chicken could have attributed to the substantially different results. Regardless, there is a consensus that immunodominant, surface-located proteins are more potent antigens since they are more accessible for inducing antibody production. For this reason, as evidenced in the above work, most antigens vetted for Campylobacter vaccine development have been extracellular in nature (Kobierecka et al., 2016).

In addition to development of poultry vaccines, there has been a considerable amount of research toward the development of a Campylobacter vaccine for humans, which would be primarily marketed toward travelers and the military. There have been several candidates that have advanced to human testing; however, none of these candidates has been able to confer sufficient protection to date (Maue et al., 2014).

One category of human Campylobacter vaccine that has generated considerable interest is subunit vaccines. Generally, C. jejuni strains produce lipo-oligosaccharides (LOS) that contain $\mathrm{N}$-acetyl neuraminic acid moieties that are molecular mimics of human gangliosides. Unfortunately, antibodies directed against these mimics may cross-react with human peripheral nerves, which is the pathogenic basis of GBS. Thus, whole cell oral vaccines that are at times logical for developing protection against other enteric pathogens, are not the preferred approach for vaccine development against Campylobacter (Riddle and Guerry, 2016). Regardless, a whole cell vaccine was developed, but it was unsuccessful in a phase $2 \mathrm{~b}$ challenge with C. jejuni 81-176 (Tribble et al., 2008).

Several subunit vaccines have been pursued. A flagellin subunit protein vaccine was only slightly immunogenic in phase 1 testing (Tribble et al., 2008). ACE Biosciences developed a protein subunit vaccine that was determined to be non-effective in phase 2b trials (Maue et al., 2014). Another recent study showed that a recombinant non-glycosylated C. jejuni flagellin was poorly immunogenic in Phase I trials and would likely not be effective (Riddle and Guerry, 2016). Schumack et al. developed a conjugate vaccine against the Campylobacter capsule polysaccharide (CPS) that conferred $100 \%$ protection against diarrhea from a homologous $C$. jejuni strain in a NHP model (Schumack et al., 2016). While promising, the mechanism of protection from this vaccine remains unknown.

Much effort has been leveraged toward vaccine development, since it is generally considered the most effective strategy to prevent diseases caused by viral and bacterial pathogens (Kobierecka et al., 2016). While there are obvious advantages to developing an effective Campylobacter vaccine, there are several hurdles that must be overcome. Unfortunately, vaccination is expensive due to the development and manufacturing processes. These stages are costly, complex, and lengthy, and are coupled with considerable economic and technological uncertainty (Lund and Jensen, 2016). Other disadvantages associated with vaccines is that storage is costly and time limited, and adjustment of the productive capacity is slow, expensive, and overseen by regulation. Vaccine production is characterized by economies of scale and is subject to large-scale errors (i.e., batch failures). As such, only a small fraction of all vaccine candidates reach the market (Jensen et al., 2014). In addition to these more general challenges, Campylobacter vaccine development is currently hindered by an incomplete comprehension of their protective epitopes, antigenic diversity, pathogenesis, and their association with post-infectious syndromes such as irritable bowel syndrome, reactive arthritis, and GBS (Riddle and Guerry, 2016).

\section{ANTI-Campylobacter BACTERIOCINS}

Bacteriocins are another potential treatment option that has been pursued to reduce the incidence of Campylobacter colonization 
in chickens. These proteinaceous compounds, synthesized by other bacteria, target and reduce the viability of closely related bacteria (Quereda et al., 2016). Typically, anti-Campylobacter bacteriocins are microencapsulated and administered to poultry through chicken feed. For an earlier detailed review of bacteriocins and their potential to inhibit Campylobacter in poultry, we suggest the article published by Svetoch and Stern (2010).

Prior to determining the efficacy of the bacteriocins in vivo, the proteins can be purified and characterized in vitro using inhibition zone diameter as the basis for selecting favorable anti-Campylobacter bacteriocins. This was done to describe four bacteriocins from different strains of Paenibacillus polymyxa and Bacillus circulans NRRL B-30644 (Svetoch et al., 2005). More recently, Messaoudi et al. (2012) used a purified bacteriocin from $L$. salivarius SMXD51 to decrease C. jejuni viability in vitro by $2-\log _{10}$ compared to an untreated control.

Following identification, purified bacteriocins can be administered to colonized birds. Stern et al. (2006) purified bacteriocin OR-7 from Lactobacillus salivarus NRRL B-30514 and treated chickens colonized with $C$. jejuni. Treatment with this bacteriocin reduced $C$. jejuni colonization of chickens by at least $6 \log _{10}$ compared to untreated groups (Stern et al., 2006). In another study by Stern et al. (2005), a class IIa bacteriocin secreted by Paenibacillus polymyxa NRRL B-30509 was purified and incorporated into chicken feed. Consistently, significant reductions in colonization by $C$. jejuni were observed and in one part of the study, no viable $C$. jejuni were detected in these chickens. This was in contrast to untreated birds that were colonized at a mean of $7.2 \log _{10}$ CFU/g feces (Stern et al., 2005). Similarly, another group utilized bacteriocin $\mathrm{B} 602$, secreted by $P$. polymyxa NRRL B-30509, and OR7, secreted by L. salivarius NRRL B-35014, to reduce C. coli colonization in turkey poults. In each of three separate trials, C. coli concentrations were below the level of detection in the ceca and duodenum (Cole et al., 2006).

To further develop these proteins as a treatment, subsequent studies determined whether cell-free supernatants or co-infection with bacteriocin producing strains were sufficient to eliminate Campylobacter colonization. In one study, the supernatants of L. salivarius SMXD51, L. salivarius MMS122, and L. salivarius MMS151 were shown via the formation of inhibition zones on C. jejuni and C. coli lawns to possess anti-Campylobacter compounds (Messaoudi et al., 2011). The authors concluded that bacteriocins were the cause of this inhibition as adding a proteinase led to a lack of inhibition from the supernatant. Presumably, using supernatant rather than purified bacteriocins would be preferred from an industrial standpoint, as purifying bacteriocins would add to the labor and cost of the final product (Messaoudi et al., 2011). Unfortunately, when viable L. salivarius NRRL B-30514 and P. polymyxa NRRL B-30509 were used as antagonists against Campylobacter, there was no inhibitory effect observed; this contrasted with the $6 \log _{10}$ reduction that was observed in chickens using bacteriocins purified from these strains (Stern et al., 2008). Based on this and the Messaoudi et al. (2012) study, supernatants from bacterial cultures may be a viable anti-Campylobacter treatment. However, using the bacterial strains directly as a probiotic does not seem efficacious for eliminating Campylobacter colonization.

As with any anti-Campylobacter treatment, there is the possibility strains will develop resistance to the compound. A screen for $C$. jejuni and C. coli isolates that developed resistance to the bacteriocins OR-7 and E-760 identified a C. coli strain that was significantly resistant. Analysis of this strain revealed that the multidrug efflux pump CmeABC contributed to both acquired and intrinsic resistance of the strain to the bacteriocins (Van Hoang et al., 2011b). A companion study showed that the low level of bacteriocin resistance developed by $C$. jejuni strains was not stable in the absence of selective pressure from the bacteriocins. This suggests that, while bacteriocin resistance may need to be addressed when its use becomes more widespread, the impact will likely remain transient (Van Hoang et al., 2011a).

Lastly, as with many of the above treatments, the effect of the bacteriocins on the poultry gastrointestinal microbiota is currently unknown. Fortunately, this strategy will likely be employed shortly before harvest, so concerns about the bacteriocins affecting the microbiota and influencing production efficiency are likely unfounded. Still, it would bolster the attractiveness of this approach if the specificity of the bacteriocins were known. It also needs to be determined whether the bacteriocins contaminate meat products following harvest. If this is found to occur, their stability and their effect on the human gastrointestinal environment may need to be investigated to maintain interest in this approach.

\section{CONCLUSION}

As the incidence of antibiotic resistant Campylobacter strains is increasing, the need for the development of novel non-antibiotic anti-Campylobacter treatments is becoming more critical. As such, much research is being conducted to develop treatments that either reduce Campylobacter colonization in chickens or eliminate acute infections in humans. Treatment strategies that are currently under development include anti-Campylobacter compounds, probiotics, Campylobacter-specific bacteriophage, chicken and human Campylobacter vaccines, and anti-Campylobacter bacteriocins. While several of these approaches have proven promising, it is apparent that further research is required to develop these into truly efficacious treatments. Regardless, it is encouraging that so many avenues have been, and are currently being, pursued by several talented research groups.

Further, it is necessary that the mechanisms of colonization and pathogenesis for both animals and humans is well understood, since it is likely to lead to the identification of more targets that can be used for the development of different interventions, like those mentioned above. This research need is 
particularly urgent for under-researched areas, like the impact of persistent Campylobacter colonization on the health of young children in the developing world. Hopefully, it is apparent here that the global health burden caused by Campylobacter is substantial and that these concerns are compounded by the burgeoning rates of antibiotic resistance observed in this microorganism. As such, the need to develop novel treatment strategies and conduct further research into colonization and disease mechanisms is essential in mitigating the negative effects of Campylobacter on global human health.

\section{REFERENCES}

Amour, C., Gratz, J., Mduma, E., Svensen, E., Rogawski, E. T., Mcgrath, M., et al. (2016). Epidemiology and impact of Campylobacter infection in children in 8 low-resource settings: results from the MAL-ED study. Clin. Infect. Dis. 63, 1171-1179. doi: 10.1093/cid/ciw542

Annamalai, T., Pina-Mimbela, R., Kumar, A., Binjawadagi, B., Liu, Z., Renukaradhya, G., et al. (2013). Evaluation of nanoparticle-encapsulated outer membrane proteins for the control of Campylobacter jejuni colonization in chickens. Poult. Sci. 92, 2201-2211. doi: 10.3382/ps.2012-03004

Arsi, K., Donoghue, A. M., Woo-Ming, A., Blore, P. J., and Donoghue, D. J. (2015a). The efficacy of selected probiotic and prebiotic combinations in reducing Campylobacter colonization in broiler chickens. J. Appl. Poult. Res. 24, 327-334. doi: 10.3382/japr/pfv032

Arsi, K., Donoghue, A. M., Woo-Ming, A., Blore, P. J., and Donoghue, D. J. (2015b). Intracloacal inoculation, an effective screening method for determining the efficacy of probiotic bacterial isolates against Campylobacter colonization in broiler chickens. J. Food Prot. 78, 209-213. doi: 10.4315/0362-028X.JFP14-326

Atterbury, R., Dillon, E., Swift, C., Connerton, P., Frost, J., Dodd, C., et al. (2005). Correlation of Campylobacter bacteriophage with reduced presence of hosts in broiler chicken ceca. Appl. Environ. Microbiol. 71, 4885-4887. doi: 10.1128/ AEM.71.8.4885-4887.2005

Atterbury, R. J., Connerton, P. L., Dodd, C. E., Rees, C. E., and Connerton, I. F. (2003). Isolation and characterization of Campylobacter bacteriophages from retail poultry. Appl. Environ. Microbiol. 69, 4511-4518. doi: 10.1128/AEM.69.8. 4511-4518.2003

Avci, F. Y. (2016). A chicken vaccine to protect humans from diarrheal disease. Glycobiology 26, 1137-1139. doi: 10.1093/glycob/cww097

Axelsson-Olsson, D., Waldenström, J., Broman, T., Olsen, B., and Holmberg, M. (2005). Protozoan Acanthamoeba polyphaga as a potential reservoir for Campylobacter jejuni. Appl. Environ. Microbiol. 71, 987-992. doi: 10.1128/AEM. 71.2.987-992.2005

Backert, S., Boehm, M., Wessler, S., and Tegtmeyer, N. (2013). Transmigration route of Campylobacter jejuni across polarized intestinal epithelial cells: paracellular, transcellular or both? Cell Commun. Signal. 11:72. doi: 10.1186/ 1478-811X-11-72

Bae, J., Oh, E., and Jeon, B. (2014). Enhanced transmission of antibiotic resistance in Campylobacter jejuni biofilms by natural transformation. Antimicrob. Agents Chemother. 58, 7573-7575. doi: 10.1128/AAC.04066-14

Black, R. E., Levine, M. M., Clements, M. L., Hughes, T. P., and Blaser, M. J. (1988). Experimental Campylobacter jejuni infection in humans.? J. Infect. Dis. 157, 472-479. doi: 10.1093/infdis/157.3.472

Bratz, K., Gölz, G., Janczyk, P., Nöckler, K., and Alter, T. (2015). Analysis of in vitro and in vivo effects of probiotics against Campylobacter spp. Berl. Munch. Tierarztl. Wochenschr. 128, 155-162.

Brenes, A., and Roura, E. (2010). Essential oils in poultry nutrition: main effects and modes of action. Anim. Feed Sci. Technol. 158, 1-14. doi: 10.1016/j.anifeedsci. 2010.03.007

Brüssow, H., Mcgrath, S., and Van Sinderen, D. (2007). Phage Therapy: The Western Perspective. Norfolk, VA: Caister Academy Press.

Buckley, A. M., Wang, J., Hudson, D. L., Grant, A. J., Jones, M. A., Maskell, D. J., et al. (2010). Evaluation of live-attenuated Salmonella vaccines expressing

\section{AUTHOR CONTRIBUTIONS}

TJ, JS, and JJ conceived, designed, wrote, and edited this manuscript for critical content. All authors approve this manuscript for content integrity and accuracy.

\section{FUNDING}

We acknowledge funding support from the University of Tennessee at Knoxville start-up funds.

Campylobacter antigens for control of C. jejuni in poultry. Vaccine 28, 1094-1105. doi: 10.1016/j.vaccine.2009.10.018

Carrillo, C. L., Atterbury, R., El-Shibiny, A., Connerton, P., Dillon, E., Scott, A., et al. (2005). Bacteriophage therapy to reduce Campylobacter jejuni colonization of broiler chickens. Appl. Environ. Microbiol. 71, 6554-6563. doi: 10.1128/AEM. 71.11.6554-6563.2005

Carrillo, C. M. L., Connerton, P. L., Pearson, T., and Connerton, I. F. (2007). Freerange layer chickens as a source of Campylobacter bacteriophage. Antonie Van Leeuwenhoek 92, 275-284. doi: 10.1007/s10482-007-9156-4

Clark, J. D., Oakes, R. D., Redhead, K., Crouch, C. F., Francis, M. J., Tomley, F. M., et al. (2012). Eimeria species parasites as novel vaccine delivery vectors: antiCampylobacter jejuni protective immunity induced by Eimeria tenella-delivered CjaA. Vaccine 30, 2683-2688. doi: 10.1016/j.vaccine.2012.02.002

Coker, A. O., Isokpehi, R. D., Thomas, B. N., Amisu, K. O., and Obi, C. L. (2002). Human campylobacteriosis in developing countries-synopsis-statistical data included. Emerg. Infect. Dis. 8, 237-243. doi: 10.3201/eid0803.010233

Cole, K., Farnell, M., Donoghue, A., Stern, N., Svetoch, E., Eruslanov, B., et al. (2006). Bacteriocins reduce Campylobacter colonization and alter gut morphology in turkey poults. Poult. Sci. 85, 1570-1575. doi: 10.1093/ps/85.9. 1570

Connerton, I., Connerton, P., Barrow, P., Seal, B., Atterbury, R., Nachamkin, I., et al. (2008). "Campylobacter and their bacteriophage in poultry," in Avian Gut Function in Health and Disease, ed. G. C. Perry (Cambridge, MA: CAB International), 679-693.

Connerton, P., Carrillo, C. L., Swift, C., Dillon, E., Scott, A., Rees, C., et al. (2004). Longitudinal study of Campylobacter jejuni bacteriophages and their hosts from broiler chickens. Appl. Environ. Microbiol. 70, 3877-3883. doi: 10.1128/AEM. 70.7.3877-3883.2004

Connerton, P. L., Timms, A. R., and Connerton, I. F. (2011). Campylobacter bacteriophages and bacteriophage therapy. J. Appl. Microbiol. 111, 255-265. doi: 10.1111/j.1365-2672.2011.05012.x

De Zoete, M. R., Van Putten, J. P., and Wagenaar, J. A. (2007). Vaccination of chickens against Campylobacter. Vaccine 25, 5548-5557. doi: 10.1016/j.vaccine. 2006.12.002

Duarte, A., Luís, Â., Oleastro, M., and Domingues, F. C. (2016). Antioxidant properties of coriander essential oil and linalool and their potential to control Campylobacter spp. Food Control 61, 115-122. doi: 10.1016/j.foodcont.2015. 09.033

EFSA (2014). European Union summary report on antimicrobial resistance in zoonotic and indicator bacteria from humans, animals and food. Euro surveillance: bulletin Européen sur les maladies transmissibles. Eur. Commun. Dis. Bull. 19:20748. doi: 10.2903/j.efsa.2016.4380

El-Shibiny, A., Connerton, P., and Connerton, I. (2005). Enumeration and diversity of campylobacters and bacteriophages isolated during the rearing cycles of free-range and organic chickens. Appl. Environ. Microbiol. 71, 1259-1266. doi: 10.1128/AEM.71.3.1259-1266.2005

El-Shibiny, A., Scott, A., Timms, A., Metawea, Y., Connerton, P., and Connerton, I. (2009). Application of a group II Campylobacter bacteriophage to reduce strains of Campylobacter jejuni and Campylobacter coli colonizing broiler chickens. J. Food Prot. 72, 733-740. doi: 10.4315/0362-028X-72.4.733

Elvers, K. T., and Park, S. F. (2002). Quorum sensing in Campylobacter jejuni: detection of a luxS encoded signalling molecule. Microbiology 148, 1475-1481. doi: 10.1099/00221287-148-5-1475 
El-Zamkan, M. A., and Hameed, K. G. A. (2016). Prevalence of Campylobacter jejuni and Campylobacter coli in raw milk and some dairy products. Vet. World 9, 1147-1151. doi: 10.14202/vetworld.2016.11471151

Fanelli, A., Agazzi, A., Alborali, G. L., Pilotto, A., Bontempo, V., Dell'orto, V., et al. (2015). Prevalence reduction of pathogens in poultry fed with Saccharomyces cerevisiae. Biotechnol. Agron. Soc. Environ. 19, 3-10.

Fox, J., Ackerman, J., Taylor, N., Claps, M., and Murphy, J. (1987). Campylobacter jejuni infection in the ferret: an animal model of human campylobacteriosis. Am. J. Vet. Res. 48, 85-90.

Gillespie, I. A., O’brien, S. J., Frost, J. A., Adak, G. K., Horby, P., Swan, A. V., et al. (2002). A case-case comparison of Campylobacter coli and Campylobacter jejuni infection: a tool for generating hypotheses. Emerg. Infect. Dis. 8, 937-942. doi: 10.3201/eid0809.010187

Goldstein, R. E. R., Cruz-Cano, R., Jiang, C., Palmer, A., Blythe, D., Ryan, P., et al. (2016). Association between community socioeconomic factors, animal feeding operations, and campylobacteriosis incidence rates: Foodborne Diseases Active Surveillance Network (FoodNet), 2004-2010. BMC Infect. Dis. 16:354 doi: 10.1186/s12879-016-1686-9

Gracia, M. I., Millan, C., Sanchez, J., Guyard-Nicodeme, M., Mayot, J., Carre, Y., et al. (2016). Efficacy of feed additives against Campylobacter in live broilers during the entire rearing period: part B. Poult. Sci. 95, 886-892. doi: 10.3382/ ps/pev346

Grajewski, B., Kusek, J., and Gelfand, H. (1985). Development of a bacteriophage typing system for Campylobacter jejuni and Campylobacter coli. J. Clin. Microbiol. 22, 13-18.

Grant, A., Hashem, F., and Parveen, S. (2016). Salmonella and Campylobacter: antimicrobial resistance and bacteriophage control in poultry. Food Microbiol. 53, 104-109. doi: 10.1016/j.fm.2015.09.008

Guerry, P., Poly, F., Riddle, M., Maue, A. C., Chen, Y.-H., and Monteiro, M. A. (2012). "Campylobacter polysaccharide capsules: virulence and vaccines," in Research Advances in the Study of Campylobacter, Helicobacter \& Related Organisms, ed. A. Stintzi (Washington, DC: Institute of Systems Biology), 146.

Guyard-Nicodeme, M., Keita, A., Quesne, S., Amelot, M., Poezevara, T., Le Berre, B., et al. (2016). Efficacy of feed additives against Campylobacter in live broilers during the entire rearing period. Poult. Sci. 95, 298-305. doi: 10.3382/ ps/pev303

Hakkinen, M., Heiska, H., and Hanninen, M. L. (2007). Prevalence of Campylobacter spp. in cattle in Finland and antimicrobial susceptibilities of bovine Campylobacter jejuni strains. Appl. Environ. Microbiol. 73, 3232-3238. doi: 10.1128/AEM.02579-06

Hampton, T. (2013). Report reveals scope of US antibiotic resistance threat. JAMA 310, 1661-1663. doi: 10.1001/jama.2013.280695

Hamrita, T. K., and Conway, R. H. (2017). Effect of air velocity on deep body temperature and weight gain in the broiler chicken. J. Appl. Poult. Res. 26, 111-121. doi: 10.3382/japr/pfw051

Han, K., Jang, S. S., Choo, E., Heu, S., and Ryu, S. (2007). Prevalence, genetic diversity, and antibiotic resistance patterns of Campylobacter jejuni from retail raw chickens in Korea. Int. J. Food Microbiol. 114, 50-59. doi: 10.1016/j. ijfoodmicro.2006.10.042

Hansen, V. M., Rosenquist, H., Baggesen, D. L., Brown, S., and Christensen, B. B. (2007). Characterization of Campylobacter phages including analysis of host range by selected Campylobacter Penner serotypes. BMC Microbiol. 7:90. doi: 10.1186/1471-2180-7-90

Huang, J.-L., Yin, Y.-X., Pan, Z.-M., Zhang, G., Zhu, A.-P., Liu, X.-F., et al. (2010). Intranasal immunization with chitosan/pCAGGS-flaA nanoparticles inhibits Campylobacter jejuni in a white leghorn model. J. Biomed. Res. Int. 2010:589476. doi: $10.1155 / 2010 / 589476$

Humphrey, S., Chaloner, G., Kemmett, K., Davidson, N., Williams, N., Kipar, A., et al. (2014). Campylobacter jejuni is not merely a commensal in commercial broiler chickens and affects bird welfare. mBio 5: e01364-14. doi: 10.1128/mBio. 01364-14

Jensen, J. D., Lund, M., and Fabricius, O. (2014). Economic Analysis of Developing a Campylobacter Vaccine to Poultry: a Real Options Approach. IFRO Report No. 227. Copenhagen: Fredericksberg: Department of Food and Resource Economics, University of Copenhagen.

Johnson, J. G., Yuhas, C., Mcquade, T. J., Larsen, M. J., and Dirita, V. J. (2015). Narrow-spectrum inhibitors of Campylobacter jejuni flagellar expression and growth. Antimicrob. Agents Chemother. 59, 3880-3886. doi: 10.1128/AAC. 04926-14

Johnston, S. A., Voelz, K., and May, R. C. (2016). Cryptococcus neoformans thermotolerance to avian body temperature is sufficient for extracellular growth but not intracellular survival in macrophages. Sci. Rep. 6:20977. doi: 10.1038/ srep20977

Jonaidi-Jafari, N., Khamesipour, F., Ranjbar, R., and Kheiri, R. (2016). Prevalence and antimicrobial resistance of Campylobacter species isolated from the avian eggs. Food Control 70, 35-40. doi: 10.1016/j.foodcont.2016.05.018

Kaakoush, N. O., Castaño-Rodríguez, N., Mitchell, H. M., and Man, S. M. (2015). Global epidemiology of Campylobacter infection. Clin. Microbiol. Rev. 28, 687-720. doi: 10.1128/CMR.00006-15

Kaakoush, N. O., Mitchell, H. M., and Man, S. M. (2014a). Role of emerging Campylobacter species in inflammatory bowel diseases. Inflamm. Bowel Dis. 20, 2189-2197. doi: 10.1097/MIB.0000000000000074

Kaakoush, N. O., Sodhi, N., Chenu, J. W., Cox, J. M., Riordan, S. M., and Mitchell, H. M. (2014b). The interplay between Campylobacter and Helicobacter species and other gastrointestinal microbiota of commercial broiler chickens. Gut Pathog. 6:18. doi: 10.1186/1757-4749-6-18

Kalmokoff, M., Lanthier, P., Tremblay, T.-L., Foss, M., Lau, P. C., Sanders, G., et al. (2006). Proteomic analysis of Campylobacter jejuni 11168 biofilms reveals a role for the motility complex in biofilm formation. J. Bacteriol. 188, 4312-4320. doi: 10.1128/JB.01975-05

Kärenlampi, R., and Hänninen, M.-L. (2004). Survival of Campylobacter jejuni on various fresh produce. Int. J. Food Microbiol. 97, 187-195. doi: 10.1016/j. ijfoodmicro.2004.04.019

Kemmett, K. (2015). Probiotics and enzymes: a good combination: feed science. AFMA Matrix 24, 35-37.

Kettle, H., Louis, P., Holtrop, G., Duncan, S. H., and Flint, H. J. (2015). Modelling the emergent dynamics and major metabolites of the human colonic microbiota. Environ. Microbiol. 17, 1615-1630. doi: 10.1111/1462-2920.12599

Khoury, C., and Meinersmann, R. (1995). A genetic hybrid of the Campylobacter jejuni flaA gene with LT-B of Escherichia coli and assessment of the efficacy of the hybrid protein as an oral chicken vaccine. Avian Dis. 39, 812-820. doi: $10.2307 / 1592418$

Klanènik, A., Možina, S. S., and Zhang, Q. (2012). Anti-Campylobacter activities and resistance mechanisms of natural phenolic compounds in Campylobacter. PLoS ONE 7:e51800. doi: 10.1371/journal.pone.0051800

Kobierecka, P. A., Wyszyñska, A. K., Gubernator, J., Kuczkowski, M., Wiśniewski, O., Maruszewska, M., et al. (2016). Chicken anti-Campylobacter vaccine-comparison of various carriers and routes of immunization. Front. Microbiol. 7:740. doi: 10.3389/fmicb.2016.00740

Kovač, J., Čadež, N., Stessl, B., Stingl, K., Gruntar, I., Ocepek, M., et al. (2015). High genetic similarity of ciprofloxacin-resistant Campylobacter jejuni in central Europe. Front. Microbiol. 6:1169. doi: 10.3389/fmicb.2015. 01169

Kumar, A., Drozd, M., Pina-Mimbela, R., Xu, X., Helmy, Y. A., Antwi, J., et al. (2016). Novel anti-Campylobacter compounds identified using high throughput screening of a pre-selected enriched small molecules library. Front. Microbiol. 7:405. doi: 10.3389/fmicb.2016.00405

Layton, S., Morgan, M., Cole, K., Kwon, Y., Donoghue, D., Hargis, B., et al. (2011). Evaluation of Salmonella-vectored Campylobacter peptide epitopes for reduction of Campylobacter jejuni in broiler chickens. Clin. Vaccine Immunol. 18, 449-454. doi: 10.1128/CVI.00379-10

Lehtola, M. J., Pitkänen, T., Miebach, L., and Miettinen, I. T. (2006). Survival of Campylobacter jejuni in potable water biofilms: a comparative study with different detection methods. Water Sci. Technol. 54, 57. doi: 10.2166/wst. 2006.448

Lin, J., Michel, L. O., and Zhang, Q. (2002). CmeABC functions as a multidrug efflux system in Campylobacter jejuni. Antimicrob. Agents Chemother. 46, 2124-2131. doi: 10.1128/AAC.46.7.2124-2131.2002

Longenberger, A. H., Palumbo, A. J., Chu, A. K., Moll, M. E., Weltman, A., and Ostroff, S. M. (2013). Campylobacter jejuni infections associated with unpasteurized milk-multiple states, 2012. Clin. Infect. Dis. 57, 263-266. doi: $10.1093 / \mathrm{cid} / \mathrm{cit} 231$

Lu, X., Rasco, B. A., Jabal, J. M., Aston, D. E., Lin, M., and Konkel, M. E. (2011). Investigating antibacterial effects of garlic (Allium sativum) concentrate and garlic-derived organosulfur compounds on Campylobacter jejuni by using 
Fourier transform infrared spectroscopy, Raman spectroscopy, and electron microscopy. Appl. Environ. Microbiol. 77, 5257-5269. doi: 10.1128/AEM. 02845- 10

Lund, M., and Jensen, J. D. (2016). A real options approach to biotechnology investment policy - the case of developing a Campylobacter vaccine to poultry. Prev. Vet. Med. 128, 58-69. doi: 10.1016/j.prevetmed.2016.04.006

Maal-Bared, R., Bartlett, K. H., Bowie, W. R., and Hall, E. R. (2012). Campylobacter spp. distribution in biofilms on different surfaces in an agricultural watershed (Elk Creek, British Columbia): using biofilms to monitor for Campylobacter. Int. J. Hyg. Environ. Health 215, 270-278. doi: 10.1016/j.ijheh.2011.12.004

Manyi-Loh, C. E., Mamphweli, S. N., Meyer, E. L., Makaka, G., Simon, M., and Okoh, A. I. (2016). An overview of the control of bacterial pathogens in cattle manure. Int. J. Environ. Res. Public Health 13:E843. doi: 10.3390/ ijerph13090843

Martinez, A. L., and Lin, J. (2006). Effect of an efflux pump inhibitor on the function of the multidrug efflux pump $\mathrm{CmeABC}$ and antimicrobial resistance in Campylobacter. Foodborne Pathog. Dis. 3, 393-402. doi: 10.1089/fpd.2006.3.393

Maue, A. C., Poly, F., and Guerry, P. (2014). A capsule conjugate vaccine approach to prevent diarrheal disease caused by Campylobacter jejuni. Hum. Vaccines Immunother. 10, 1499-1504. doi: 10.4161/hv.27985

Messaoudi, S., Kergourlay, G., Dalgalarrondo, M., Choiset, Y., Ferchichi, M., Prévost, H., et al. (2012). Purification and characterization of a new bacteriocin active against Campylobacter produced by Lactobacillus salivarius SMXD51. Food Microbiol. 32, 129-134. doi: 10.1016/j.fm.2012.05.002

Messaoudi, S., Kergourlay, G., Rossero, A., Ferchichi, M., Prévost, H., Drider, D., et al. (2011). Identification of lactobacilli residing in chicken ceca with antagonism against Campylobacter. Int. Microbiol. 14, 103-110. doi: 10.2436/ 20.1501.01.140

Meunier, M., Guyard-Nicodeme, M., Dory, D., and Chemaly, M. (2016a). Control strategies against Campylobacter at the poultry production level: biosecurity measures, feed additives and vaccination. J. Appl. Microbiol. 120, 1139-1173. doi: $10.1111 /$ jam. 12986

Meunier, M., Guyard-Nicodème, M., Hirchaud, E., Parra, A., Chemaly, M., and Dory, D. (2016b). Identification of novel vaccine candidates against Campylobacter through reverse vaccinology. J. Immunol. Res. 2016:5715790. doi: 10.1155/2016/5715790

Mohan, V. (2015). The role of probiotics in the inhibition of Campylobacter jejuni colonization and virulence attenuation. Eur. J. Clin. Microbiol. Infect. Dis. 34, 1503-1513. doi: 10.1007/s10096-015-2392-z

Moore, J. E., Barton, M. D., Blair, I. S., Corcoran, D., Dooley, J. S., Fanning, S., et al. (2006). The epidemiology of antibiotic resistance in Campylobacter. Microbes Infect. 8, 1955-1966. doi: 10.1016/j.micinf.2005.12.030

Mughini-Gras, L., Penny, C., Ragimbeau, C., Schets, F. M., Blaak, H., Duim, B., et al. (2016). Quantifying potential sources of surface water contamination with Campylobacter jejuni and Campylobacter coli. Water Res. 101, 36-45. doi: 10.1016/j.watres.2016.05.069

Navarro, M., Stanley, R., Cusack, A., and Sultanbawa, Y. (2015). Combinations of plant-derived compounds against Campylobacter in vitro. J. Appl. Poult. Res. 24, 352-363. doi: 10.3382/japr/pfv035

Nazzaro, F., Fratianni, F., and Coppola, R. (2013). Quorum sensing and phytochemicals. Int. J. Mol. Sci. 14, 12607-12619. doi: 10.3390/ijms140612607

Neal-McKinney, J. M., Samuelson, D. R., Eucker, T. P., Nissen, M. S., Crespo, R., and Konkel, M. E. (2014). Reducing Campylobacter jejuni colonization of poultry via vaccination. PLOS ONE 9:e114254. doi: 10.1371/journal.pone. 0114254

Neuman, C., Hatje, E., Stevenson, H., Smullen, R., Bowman, J., and Katouli, M. (2014). The impact of diet on the gut microbiota of Tasmanian atlantic salmon (Salmo salar L.) using a semi-continuous fermenter model. J. Appl. Environ. Microbiol. 2, 287-293.

Oh, E., and Jeon, B. (2015). Synergistic anti-Campylobacter jejuni activity of fluoroquinolone and macrolide antibiotics with phenolic compounds. Front. Microbiol. 6:1129. doi: 10.3389/fmicb.2015.01129

Pagès, J.-M., and Amaral, L. (2009). Mechanisms of drug efflux and strategies to combat them: challenging the efflux pump of gram-negative bacteria. Biochim. Biophys. Acta 1794, 826-833. doi: 10.1016/j.bbapap.2008.12.011

Pelfrene, E., Willebrand, E., Sanches, A. C., Sebris, Z., and Cavaleri, M. (2016). Bacteriophage therapy: a regulatory perspective. J. Antimicrob. Chemother. 71, 2071-2074. doi: 10.1093/jac/dkw083
Peng, M., Reichmann, G., and Biswas, D. (2015). Lactobacillus casei and its byproducts alter the virulence factors of foodborne bacterial pathogens. J. Funct. Foods 15, 418-428. doi: 10.1016/j.jff.2015.03.055

Pérez-Boto, D., Herrera-León, S., Garcia-Pena, F. J., Abad-Moreno, J. C., and Echeita, M. A. (2014). Molecular mechanisms of quinolone, macrolide, and tetracycline resistance among Campylobacter isolates from initial stages of broiler production. Avian Pathol. 43, 176-182. doi: 10.1080/03079457.2014. 898245

Pogačar, M. Š., Klančnik, A., Bucar, F., Langerholc, T., and Možina, S. S. (2015). Alpinia katsumadai extracts inhibit adhesion and invasion of Campylobacter jejuni in animal and human foetal small intestine cell lines. Phytother. Res. 29, 1585-1589. doi: 10.1002/ptr.5396

Quereda, J. J., Dussurget, O., Nahori, M.-A., Ghozlane, A., Volant, S., Dillies, M.-A., et al. (2016). Bacteriocin from epidemic Listeria strains alters the host intestinal microbiota to favor infection. Proc. Natl Acad. Sci. U.S.A. 113, 5706-5711. doi: 10.1073/pnas.1523899113

Ricotta, E. E., Palmer, A., Wymore, K., Clogher, P., Oosmanally, N., Robinson, T., et al. (2014). Epidemiology and antimicrobial resistance of international travelassociated Campylobacter infections in the United States, 2005-2011. Am. J. Public Health 104, e108-e114. doi: 10.2105/AJPH.2013.301867

Riddle, M. S., and Guerry, P. (2016). Status of vaccine research and development for Campylobacter jejuni. Vaccine 34, 2903-2906. doi: 10.1016/j.vaccine.2016. 02.080

Robinson, D. A. (1981). Infective dose of Campylobacter jejuni in milk. Br. Med. J. 282:1584. doi: $10.1136 / \mathrm{bmj} .282 .6276 .1584$

Rosenquist, H., Nielsen, N. L., Sommer, H. M., Nørrung, B., and Christensen, B. B. (2003). Quantitative risk assessment of human campylobacteriosis associated with thermophilic Campylobacter species in chickens. Int. J. Food Microbiol. 83, 87-103. doi: 10.1016/S0168-1605(02)00317-3

Sahin, O., Luo, N., Huang, S., and Zhang, Q. (2003). Effect of Campylobacterspecific maternal antibodies on Campylobacter jejuni colonization in young chickens. Appl. Environ. Microbiol. 69, 5372-5379. doi: 10.1128/AEM.69.9. 5372-5379.2003

Saint-Cyr, M. J., Guyard-Nicodème, M., Messaoudi, S., Chemaly, M., Cappelier, J. M., Dousset, X., et al. (2016). Recent advances in screening of antiCampylobacter activity in probiotics for use in poultry. Front. Microbiol. 7:553. doi: $10.3389 /$ fmicb. 2016.00553

Salama, S., Bolton, F., and Hutchinson, D. (1989). Improved method for the isolation of Campylobacter jejuni and Campylobacter coli bacteriophages. Lett. Appl. Microbiol. 8, 5-7. doi: 10.1111/j.1472-765X.1989. tb00211.x

Samuelson, D. R., Eucker, T. P., Bell, J. A., Dybas, L., Mansfield, L. S., and Konkel, M. E. (2013). The Campylobacter jejuni CiaD effector protein activates MAP kinase signaling pathways and is required for the development of disease. Cell Commun. Signal. 11:79. doi: 10.1186/1478-811X-11-79

Saxena, M., John, B., Mu, M., Van, T. T. H., Taki, A., Coloe, P. J., et al. (2013). Strategies to reduce Campylobacter colonisation in chickens. Procedia Vaccinol. 7, 40-43. doi: 10.1016/j.provac.2013.06.008

Schumack, N. M., Rimmer, J. E., Guerry, P., and Laird, R. M. (2016). Functional complement-fixing antibodies are generated against a Campylobacter jejuni capsule conjugate vaccine in non-human primates. J. Immunol. 196, 146.122 .

Serichantalergs, O., Dalsgaard, A., Bodhidatta, L., Krasaesub, S., Pitarangsi, C., Srijan, A., et al. (2007). Emerging fluoroquinolone and macrolide resistance of Campylobacter jejuni and Campylobacter coli isolates and their serotypes in Thai children from 1991 to 2000. Epidemiol. Infect. 135, 1299-1306. doi: $10.1017 /$ S0950268807008096

Shane, S. (2000). Campylobacter infection of commercial poultry. Rev. Sci. Tech. 19, 376-385. doi: 10.20506/rst.19.2.1224

Šikić Pogačar, M., Klančnik, A., Bucar, F., Langerholc, T., and Smole Možina, S. (2015). Anti-adhesion activity of thyme (Thymus vulgaris L.) extract, thyme post-distillation waste, and olive (Olea europea L.) leaf extract against Campylobacter jejuni on polystyrene and intestine epithelial cells. J. Sci. Food Agric. 96, 2723-2730. doi: 10.1002/jsfa.7391

Simões, L. C., Simoes, M., and Vieira, M. J. (2010). Influence of the diversity of bacterial isolates from drinking water on resistance of biofilms to disinfection. Appl. Environ. Microbiol. 76, 6673-6679. doi: 10.1128/AEM. 00872-10 
Smith, H. W., Huggins, M. B., and Shaw, K. M. (1987). The control of experimental Escherichia coli diarrhoea in calves by means of bacteriophages. Microbiology 133, 1111-1126. doi: 10.1099/00221287-133-5-1111

Stahl, M., Ries, J., Vermeulen, J., Yang, H., Sham, H. P., Crowley, S. M., et al. (2014). A novel mouse model of Campylobacter jejuni gastroenteritis reveals key proinflammatory and tissue protective roles for Toll-like receptor signaling during infection. PLoS Pathog. 10:e1004264. doi: 10.1371/journal.ppat.1004264

Ştef, L. (2016). Evaluation of the administration effects of probiotics against Campylobacter jejuni on the immune system of broiler chickens. Sci. Pap. Anim. Sci. Biotechnol. 49, 16-21. doi: 10.1371/journal.ppat.1004264

Stern, N., Svetoch, E., Eruslanov, B., Perelygin, V., Mitsevich, E., Mitsevich, I., et al. (2006). Isolation of a Lactobacillus salivarius strain and purification of its bacteriocin, which is inhibitory to Campylobacter jejuni in the chicken gastrointestinal system. Antimicrob. Agents Chemother. 50, 3111-3116. doi: 10.1128/AAC.00259-06

Stern, N. J., Eruslanov, B. V., Pokhilenko, V. D., Kovalev, Y. N., Volodina, L. L., Perelygin, V. V., et al. (2008). Bacteriocins reduce Campylobacter jejuni colonization while bacteria producing bacteriocins are ineffective. Microb. Ecol. Health Dis. 20, 74-79. doi: 10.1080/08910600802030196

Stern, N. J., Svetoch, E. A., Eruslanov, B. V., Kovalev, Y. N., Volodina, L. I., Perelygin, V. V., et al. (2005). Paenibacillus polymyxa purified bacteriocin to control Campylobacter jejuni in chickens. J. Food Prot. 68, 1450-1453. doi: 10.4315/0362-028X-68.7.1450

Sumeri, I., Arike, L., Adamberg, K., and Paalme, T. (2008). Single bioreactor gastrointestinal tract simulator for study of survival of probiotic bacteria. Appl. Microbiol. Biotechnol. 80, 317-324. doi: 10.1007/s00253-008-1553-8

Sung, J., Morales, W., Kim, G., Pokkunuri, V., Weitsman, S., Rooks, E., et al. (2013). Effect of repeated Campylobacter jejuni infection on gut flora and mucosal defense in a rat model of post infectious functional and microbial bowel changes. Neurogastroenterol. Motil. 25, 529-537. doi: 10.1111/nmo. 12118

Svetoch, E., and Stern, N. (2010). Bacteriocins to control Campylobacter spp. in poultry-a review. Poult. Sci. 89, 1763-1768. doi: 10.3382/ps.2010-00659

Svetoch, E. A., Stern, N. J., Eruslanov, B. V., Kovalev, Y. N., Volodina, L. I., Perelygin, V. V., et al. (2005). Isolation of Bacillus circulans and Paenibacillus polymyxa strains inhibitory to Campylobacter jejuni and characterization of associated bacteriocins. J. Food Prot. 68, 11-17. doi: 10.4315/0362-028X-68.1.11

Szymanski, C., and Nothaft, H. (2016). Campylobacter vaccine. US 2016004 $5584 \mathrm{~A} 1$.

Tee, W., and Mijch, A. (1998). Campylobacter jejuni bacteremia in human immunodeficiency virus (HIV)-infected and non-HIV-infected patients: comparison of clinical features and review. Clin. Infect. Dis. 26, 91-96. doi: $10.1086 / 516263$

Ternhag, A., Asikainen, T., Glesecke, J., and Ekdahl, K. (2007). A meta-analysis on the effects of antibiotic treatment on duration of symptoms caused by infection with Campylobacter species. Clin. Infect. Dis.? 44, 696-700. doi: 10.1086/ 509924

Theoret, J. R., Cooper, K. K., Zekarias, B., Roland, K. L., Law, B. F., Curtiss, R., et al. (2012). The Campylobacter jejuni Dps homologue is important for in vitro biofilm formation and cecal colonization of poultry and may serve as a protective antigen for vaccination. Clin. Vaccine Immunol. 19, 1426-1431. doi: 10.1128/CVI.00151-12

Thomrongsuwannakij, T., Chuanchuen, R., and Chansiripornchai, N. (2016). Identification of competitive exclusion and its ability to protect against Campylobacter jejuni in broilers. Thai J. Vet. Med. 46, 279-286.

Tribble, D., Baqar, S., and Thompson, S. (2008). "Development of a human vaccine," in Campylobacter, 3rd Edn, eds I. Nachamkin, C. Szymanski, and M. Blaser (Washington, DC: ASM Press), 429-444.

Van Hoang, K., Norman, N. J., and Lin, J. (2011a). Development and stability of bacteriocin resistance in Campylobacter spp. J. Appl. Microbiol. 111, 1544-1550. doi: $10.1111 / j .1365-2672.2011 .05163 . x$
Van Hoang, K., Stern, N. J., Saxton, A. M., Xu, F., Zeng, X., and Lin, J. (2011b). Prevalence, developments, and molecular mechanisms of bacteriocin resistance in Campylobacter. Appl. Environ. Microbiol. 77, 2309-2316. doi: 10.1128/AEM. 02094-10

Verbeke, W., Frewer, L. J., Scholderer, J., and De Brabander, H. F. (2007). Why consumers behave as they do with respect to food safety and risk information. Anal. Chim. Acta 586, 2-7. doi: 10.1016/j.aca.2006.07.065

Wagenaar, J. A., Van Bergen, M. A. P., Mueller, M. A., Wassenaar, T. M., and Carlton, R. M. (2005). Phage therapy reduces Campylobacter jejuni colonization in broilers. Vet. Microbiol. 109, 275-283. doi: 10.1016/j.vetmic.2005.06.002

Wang, G., Zhao, Y., Tian, F., Jin, X., Chen, H., Liu, X., et al. (2014). Screening of adhesive lactobacilli with antagonistic activity against Campylobacter jejuni. Food Control 44, 49-57. doi: 10.1016/j.foodcont.2014.03.042

Wang, Y., and Taylor, D. (1990). Natural transformation in Campylobacter species. J. Bacteriol. 172, 949-955. doi: 10.1128/jb.172.2.949-955.1990

Weis, A. M., Storey, D. B., Taff, C. C., Townsend, A. K., Huang, B. C., Kong, N. T., et al. (2016). Genomic comparisons and zoonotic potential of Campylobacter between birds, primates, and livestock. Appl. Environ. Microbiol. 82, 7165-7175. doi: 10.1128/AEM.01746-16

Widders, P., Thomas, L., Long, K., Tokhi, M., Panaccio, M., and Apos, E. (1998). The specificity of antibody in chickens immunised to reduce intestinal colonisation with Campylobacter jejuni. Vet. Microbiol. 64, 39-50. doi: 10.1016/ S0378-1135(98)00251-X

Wieczorek, K., and Osek, J. (2013). Antimicrobial resistance mechanisms among Campylobacter. Biomed. Res. Int. 2013:340605. doi: 10.1155/2013/340605

Wilson, D. L., Bell, J. A., Young, V. B., Wilder, S. R., Mansfield, L. S., and Linz, J.E. (2003). Variation of the natural transformation frequency of Campylobacter jejuni in liquid shake culture. Microbiology 149, 3603-3615. doi: 10.1099/mic.0. 26531-0

Wine, E., Gareau, M. G., Johnson-Henry, K., and Sherman, P. M. (2009). Strain-specific probiotic (Lactobacillus helveticus) inhibition of Campylobacter jejuni invasion of human intestinal epithelial cells. FEMS Microbiol. Lett. 300, 146-152. doi: 10.1111/j.1574-6968.2009.01781.x

Wooten, J., Liu, X., and Miller, M. J. (2016). Draft genome sequence of Lactobacillus crispatus JCM5810, which can reduce Campylobacter jejuni colonization in chicken intestine. Genome Announc. 4, e255-e216. doi: 10.1128/genomeA. 00255-16

Wright, G. D. (2000). Resisting resistance: new chemical strategies for battling superbugs. Chem. Biol. 7, R127-R132. doi: 10.1016/S1074-5521(00)00126-5

Wyszyńska, A., Raczko, A., Lis, M., and Jagusztyn-Krynicka, E. K. (2004). Oral immunization of chickens with avirulent Salmonella vaccine strain carrying C. jejuni 72Dz/92 cjaA gene elicits specific humoral immune response associated with protection against challenge with wild-type Campylobacter. Vaccine 22, 1379-1389. doi: 10.1016/j.vaccine.2003.11.001

Young, K. T., Davis, L. M., and Dirita, V. J. (2007). Campylobacter jejuni: molecular biology and pathogenesis. Nat. Rev. Microbiol. 5, 665-679. doi: $10.1038 /$ nrmicrol718

Zeng, X., Xu, F., and Lin, J. (2010). Development and evaluation of CmeC subunit vaccine against Campylobacter jejuni. J. Vaccines Vaccin. 1:112. doi: 10.4172/ 2157-7560.1000112

Conflict of Interest Statement: The authors declare that the research was conducted in the absence of any commercial or financial relationships that could be construed as a potential conflict of interest.

Copyright (c) 2017 Johnson, Shank and Johnson. This is an open-access article distributed under the terms of the Creative Commons Attribution License (CC BY). The use, distribution or reproduction in other forums is permitted, provided the original author(s) or licensor are credited and that the original publication in this journal is cited, in accordance with accepted academic practice. No use, distribution or reproduction is permitted which does not comply with these terms. 